\title{
Elementos para a tradução do octossílabo em português
}

Álvaro Faleiros

Apesar de algumas vozes dissonantes, como a de Ledo lvo (1982: 69), para quem, "talvez, a melhor maneira de traduzir-se um poema, sem tisnar ou martirizar a sua magia nativa, seja a prosa", a maioria dos tradutores de textos poéticos procura, hoje, no Brasil, produzir, na língua de chegada, textos que sejam homólogos' aos textos de partida, não apenas no plano do conteúdo, mas igualmente no da expressão, visto que, no poema, este é um plano constitutivo de seu modo de significar.

Uma das dimensões importantes no plano da expressão é o metro dos poemas. Desde os gregos e latinos, no ocidente, determinados gêneros literários vinculam-se ao número de pés que constituem seus versos. Este é, aliás, um dos elementos centrais nas poéticas românicas medievais. Nessas línguas modernas por exemplo, em francês e em espanhol - um dos metros mais usuais é o octossílabo.

Dentre os versos da língua francesa, segundo Lote (1949), o octossílabo é o primeiro e mais universal de todos: "No século XV, ele balança a fortuna do decassílabo e sobressai a este. É o verso favorito de Villon, dos poemas dramáticos sérios e dos autores de farsas. Assim, ele atravessa toda a Idade Média e sua força não é 
em nada diminuída quando chega à época moderna ${ }^{2 \prime \prime}$ (Lote, 1949: 58-59). Um exemplo de octossílabo é esta estrofe de Musset:

\section{$12 \quad 345678$}

Du temps que j'étais écolier Je restais un soir à veiller Dans notre salle solitaire.

Devant ma table vint s'asseior Un pauvre enfant vétu de noir, Qui me ressemblait comme un frère.

Quanto à métrica espanhola, Quilis (1978: 54) assinala que o octossílabo é o mais importante verso de arte menor e o mais antigo da poesia espanhola. Esse metro é, até hoje, empregado tanto pelos poetas populares, como pelos maiores poetas da lírica espanhola. Quilis cita, como exemplo, a quadrinha popular:

\section{$\begin{array}{llllllll}1 & 2 & 3 & 4 & 5 & 6 & 7 & 8\end{array}$}

Cuen-ta-le al-mun-do-tus-di-chas, y no le cuentes tus penas, que mejor es que te envidien que no que te compadezcan

Pode-se notar, pelos exemplos acima, que o francês e o espanhol diferem no modo de contar as sílabas. Na tradição francesa, conta-se o verso até a última sílaba tônica e, em espanhol, conta-se até uma sílaba átona após a tônica. Esta diferença explica-se pelo fato de que a língua francesa é uma língua em que os vocábulos são oxítonos (agudos), enquanto que o espanhol é uma língua em que os vocábulos são, em sua grande maioria, paroxítonos (graves), como em português. 
Apesar de o português ser uma língua de índole grave como o espanhol, seu sistema de contagem não coincide sempre com o do espanhol. Manuel Bandeira (1997: 538-539) sintetiza a questão da contagem silábica em português da seguinte forma:

Contam-se as sílabas métricas até a última vogal tônica do verso. Damos abaixo quatro versos de Artur Azevedo, grafando em itálico as sílabas contadas:

Cos-tu-mam-a-go-ra os-lí-ricos

Ver-sos-fa-zer-nes-te es-ti-lo:

"Tu-és-is-to eu-sou-a-qui-lo,

Tu-és-as-as-da eu-as-sim".

Tal sistema de contagem, também usado no idioma francês, foi introduzido em nossa língua por Antônio Feliciano de Castilho [1851] no seu Tratado de metrificação portuguesa ${ }^{3}$. Antes dele, contavamse todas as sílabas do verso grave, não se contava a última do verso esdrúxulo, e considerava-se incompleto o verso agudo, pelo que contava como duas a última sílaba métrica. Destarte, os versos de Artur de Azevedo citados acima são chamados heptassílabos (de sete sílabas) segundo o sistema de Castilho, hoje prevalecente, e octossílabos (de oito sílabas) segundo o sistema antigo, que ainda prevalece na língua espanhola, e que em nosso idioma pretende restaurar o professor M. Said Ali [1950]. Advirta-se que se trata de mera questão de nome, que não afeta a estrutura do verso.

Dentre as colocações de Bandeira note-se, primeiramente, que a tentativa de restauração do "sistema antigo" de contagem não é uma atitude isolada de Said Ali. De acordo com Chociay (1974: 13), antes dele, em 1870, Manuel da Costa Honorato em suas Synopses de eloquencia e poetica nacional já o havia feito. Leogedário Amarante de Azevedo Filho (1970: 65) adota postura semelhante e assinala que: 
FALEIROS, Álvaro. Elementos para a tradução do octossílabo em português

O verso de oito sílabas é muito freqüente na lírica francesa, sendo mesmo um verso ajustável ao ritmo predominantemente iâmbico daquele idioma. Em nossa língua, com freqüência, esse metro apresenta uma sílaba metatônica final, podendo ser considerada mesmo quando não existe, conforme a contagem espanhola, que se baseia no ritmo trocaico daquele idioma e que é idêntico ao nosso.

Recentemente, Romildo Sant'Anna (2000: 38) defende que os primeiros romances, escritos no século XIV, utilizavam geralmente "versos octossílabos (...) de acordo com o padrão grave da metrificação espanhola, mais adequado ao espírito paroxitonal da língua portuguesa. Este padrão é o adotado pelo Grupo de Estudos Literatura e Cultura Popular, UNESP de São José do Rio Preto-SP".

Chociay (1974: 13) é um dos poucos a sintetizar as duas posturas. Ainda que adote como parâmetro, em princípio, a contagem de padrão agudo, "por usualíssimo que é", ele não deixa de fazer aproximações necessárias ao padrão grave, visto que: "em verdade, certos fatos de nossa versificação (...) só ficam satisfatoriamente entendidos e explicados através desse sistema, que informou a técnica versificatória de alguns de nossos poetas arcádicos e românticos". Desse modo, a escolha de um padrão de contagem exige do tradutor uma reflexão sobre aspectos históricos e retórico-formais.

Em segundo lugar, é importante ressaltar que, se a escolha de um padrão grave ou agudo não altera a estrutura de um verso já escrito, o mesmo não ocorre na escolha de um metro no ato da tradução: se o tradutor adotar o verso octossilábico de padrão grave (espanhol), produzirá, em português, um texto em redondilhas, mas se optar pelo verso octossilábico de padrão agudo (francês) produzirá um octossílabo que corresponde a uma métrica introduzida de modo mais ou menos sistemático na língua portuguesa a partir do século XIX. De acordo com Bandeira (1997: 540): 
Os octossílabos foram raros antes de Castilho. Este escreveu: "O metro de oito, pode-se dizer que ainda não é usado em português." Acrescentando: "...quando mais e melhor cultivado, a julgarmo-lo pelos seus elementos, e pelo que os franceses dele têm chegado a fazer, pode vir a ser muito apreciado". O vaticínio realizou-se. Os poetas parnasianos serviram-se dele com freqüência ${ }^{4}$.

É revelador que nem Castilho nem Bandeira perguntam-se por que este metro é utilizado com tanta freqüência na lírica francesa desde as suas origens; o que os impede de averiguar que a poesia popular na França desenvolve-se, desde os seus primórdios, essencialmente em octossílabos. Em Portugal e no Brasil, é a redondilha que ocupa esse lugar, tanto é que Segismundo Spina (2002: 100) afirma:

O redondilho da poesia ibérica, por exemplo, é a forma de verso mais espontânea de toda a versificação peninsular. É o metro que corresponde à melodia natural das línguas hispânicas (o português, o galego, o espanhol). Nós quase falamos em redondilhos (...) $\mathrm{Na}$ primitiva poesia lírica francesa, são os versos de 8 e 10 sílabas os mais comuns.

octossílabo de padrão agudo (francês) foi, pois, praticado, sobretudo, pelos poetas da escola parnasiana, ou seja, não se trata de um metro primitivo, como o é em francês, e sim da importação de um modelo em um período específico, de grande influência francesa.

Na tradução do octossílabo francês para o português verifica-se, do mesmo modo, uma mudança de padrão exatamente no momento em que se divulga a contagem de Castilho. Uma primeira leitura de traduções (pesquisa que ainda encontra-se em curso) revela que os poetas românticos que se dedicaram à tradução de textos de seus pares franceses optaram, na maioria das 
vezes, pela tradução do octossílabo francês em redondilhas. Já nas traduções feitas por poetas parnasianos, predomina o octossílabo de padrão agudo em detrimento da redondilha. Essa prática disseminou-se entre os modernistas, como se pode verificar na antologia de Guilherme de Almeida, Poetas de França. Desde então, ao longo do século XX são quase inexistentes as traduções de octossílabos franceses por redondilhas.

A utilização de um octossílabo de padrão agudo por outro semelhante, pela sua freqüência, cria a impressão de que é o único modo de se traduzir, e por isso tal escolha nunca é justificada; o que não ocorre quando deseja-se, atualmente, traduzir octossílabos franceses em redondilhas. É o caso, por exemplo, deste artigo, inspirado em minha tese de doutorado (Faleiros, 2003) ou ainda, o caso de Rogério Duarte (1998: 22ss) que sentiu a necessidade de justificar a tradução dos clássicos versos indianos, anustubh (pada de oito sílabas) do Bhagavad Gita, por redondilhas. $O$ curioso é que, no octossílabo indiano, a última sílaba pode ser átona ou tônica.

Essa hesitação no modo de contar os versos em português é, pois, reveladora dos princípios que norteiam o trabalho do tradutor. Não se trata, aqui, de condenar um determinado uso, mas de compreender o que significa escolher um padrão acentual ou outro. É importante lembrar que considerações do tipo diacrônico "parecem indispensáveis para colher, em toda a sua espessura 'cultural', os signos da linguagem poética" (Tavani, 1983: 60), isto é, o tradutor deve estar consciente de que sua escolha situa retórico-formalmente o texto que produz também em relação às práticas poéticas da língua-meta.

Mário Laranjeira (1993: 138-139) atenta para o fato de que a fidelidade retórico-formal: "implica fatores socioculturais e lingüístico-estruturais cujo conhecimento e exame ponderado deve determinar, no sujeito-tradutor, a escolha de uma reescritura mais próxima do módulo original ou mais condizente com os usos poéticos da língua-cultura receptora". (Grifo meu). 
Uma reescritura mais próxima do original corresponderia à tradução do octossílabo francês pelo octossílabo de padrão agudo (regra de Castilho). Essa prática, hoje predominante na tradução poética no Brasil, aponta como um dos aspectos enriquecedores dessa reescritura o fato de que ela ampliaria as possibilidades poéticas da língua receptora, uma vez que o módulo da língua-fonte traz para a língua-meta elementos até então estranhos a ela.

A questão do estranhamento é, contudo mais complexa do que parece à primeira vista. Segundo Berman (2002: 18) má tradução é: "a tradução que, geralmente sob pretexto de transmissibilidade, opera uma negação sistemática da estranheza" (Grifo meu); em seguida, acrescenta que a tradução é uma forma peculiar de crítica "na medida em que ela torna manifestas as estruturas ocultas de um texto. Esse sistema-da-obra é, ao mesmo tempo, o que oferece mais resistência à tradução e o que autoriza e Ihe dá sentido". $O$ tradutor deve, pois, procurar identificar as estruturas ocultas que se articulam na obra que traduz e incorporálas em seu texto, ainda que essa tarefa seja das mais exigentes.

Para alguns poetas, a escolha de um determinado metro pode ser uma das estruturas ocultas portadoras de significados em seus textos. Apollinaire, por exemplo, opta pelo octossílabo em parte considerável de seus poemas devido a importância desse metro na poesia francesa e, em carta a André Billy, chega a afirmar: "O verso clássico vinha sendo atacado antes de mim que, contudo, utilizei-o com tanta freqüência que dei vida nova aos versos octossilábicos" (Apollinaire, 1965: 1076). Dessa maneira, ao se traduzir Apollinaire, poeta que, segundo Octávio Paz (1993: 110), "ressuscita metros medievais", a escolha da redondilha pode ser, à primeira vista, entendida como uma escolha que naturaliza o texto, mas corresponde, de fato, a uma estrutura oculta da poética apollinariana, visto que a redondilha é um verso primitivo e tradicional da lírica luso-brasileira. 
Além de incorporar uma estrutura retórico-formal oculta da poética de Apollinaire, a escolha da redondilha para se traduzir o octossílabo francês pode, hoje, no Brasil, ser uma escolha mais instigante, mais provocadora, mais estranha que a escolha de um octossílabo de padrão francês. Como afirma Jean-Lovis Bakès (2004: 88), deve-se procurar "compreender por que razão e em que condições uma comunidade está por vezes num estado de receptividade". Ora, os tradutores brasileiros dos últimos cento e cinqüenta anos estiveram mais receptivos ao padrão francês, e o utilizaram de forma sistemática em suas traduções, não praticando a tradução em redondilhas, predominante entre os românticos, estranha atualmente.

A tradução do octossílabo em redondilhas, não é, contudo, tarefa fácil e, talvez, provoque mais resistências na língua de chegada, uma vez que implica, provavelmente, uma perda maior de carga semântica, pois o tradutor contará com uma sílaba a menos em cada um de seus versos. Por outro lado, a naturalidade da redondilha pode vir a ser um facilitador na organização textual e, dessa maneira, compensar a perda. Este é, sem dúvida, um aspecto a ser considerado, mas qualquer afirmação a esse respeito é ainda precipitada, dada a falta de estudos na área.

Outra questão que se coloca é de como traduzir os poemas heptassílabos existentes em francês desde a Idade Média. Uma opção mimética resolve imediatamente a questão: sete $=$ sete, oito = oito, até a tônica final. Pode-se, contudo, optar por uma inversão numérica que implicaria uma maior fidelidade retóricoformal, isto é, traduz-se o octossílabo francês em redondilhas e o heptassílabo francês, menos utilizado mas existente na tradição, pelo octossílabo de padrão agudo. Uma terceira alternativa é fazer algo semelhante ao que alguns tradutores brasileiros fizeram, nos anos 50, com os hexâmetros e pentâmetros gregos, traduzidos ambos em decassílabos. A redondilha nesse caso serviria para octossílabos e heptassílabos franceses. 
Enfim, diferentes escolhas são possíveis, cabe ao tradutor definir seu projeto de tradução levando em consideração tanto os aspectos retórico-formais das línguas-culturas de origem e de chegada, quanto o modo como o texto e seu scriptor interagem em seus contextos. $O$ tradutor tampouco pode esquecer da singularidade do sistema de contagem métrica do português, instrumento que permite a abertura de esquecidas e promissoras trilhas.

\section{REFERÊNCIAS BIBLIOGRÁFICAS}

APOLLINAIRE, Guillaume. Oeuvres Poétiques. Paris: Gallimard, 1965. AZEVEDO FILHO, Leogedário A. Estruturalismo e crítica de poesia, Gernassa, Rio, 1970.

BACKÈS, Jean-Louis. Poética comparada. In: Compêndio de literatura comparada. BRUNEL, P. e CHEVREL, I. (org.). Tradução de Maria do Rosário Monteiro. Lisboa: Fundação Calouste Gulbenkian, 2004 [1990]. BANDEIRA, Manuel. A Versificação em Língua Portuguesa. In: Seleta de prosa. Rio de Janeiro: Nova Fronteira, 1997 [1960].

BERMAN, Antoine. A prova do estrangeiro. Tradução de Maria Emília Pereira Chanut. Bauru: EDUSC, 2002 [1984].

BILAC, Olavo e PASSOS, Guimarães. Tratado de Versificação. 8. ed. Rio de Janeiro: Francisco Alves, 1944 [1905].

CHOCIAY, Rogério. Teoria do verso. São Paulo, McGraw-Hill do Brasil, 1974.

DUARTE, Rogério. A estrutura métrica da Guita. In: Bhagavad Gita: a canção do divino mestre. São Paulo: Cia das Letras, 1998.

FALEIROS, Álvaro. Tradução e Significância nos Caligramas de Apollinaire: o espaço gráfico, o metro e a textura fônica. Doutorado. Usp, São Paulo, 2003.

IVO, Ledo. Uma temporada no inferno e iluminações. In: A tradução da grande obra literária: depoimentos. São Paulo: Álamo, 1982. 
FALEIROS, Álvaro. Elementos para a tradução do octossílabo em português

LARANJEIRA, Mário. Poética da Tradução. São Paulo: EDUSP, 1993.

LOTE, Georges. Histoire du vers français. Paris: Bovin, 1949.

PAZ, Octávio. A outra voz. São Paulo: Siciliano, 1993 [1990].

SANT'ANNA, Romildo. A moda é viola. São Paulo: Arte e Ciência, 2000.

SPINA, Segismundo. Na madrugada das formas poéticas. São Paulo: Ateliê, 2002. [1982].

TAVANI, Giuseppe. Poesia e ritmo. Lisboa: Sá da Costa, 1983.

\section{SOBRE O AUTOR}

Álvaro Faleiros é professor do Departamento de Línguas Estrangeiras e Tradução da Universidade de Brasília (UnB). Doutor em Língua e Literatura Francesa (USP), publicou, entre outras, as traduções de $O$ Bestiário, de Guillaume Apollinaire (lluminuras, 1997) e Latitudes: 9 poetas do Québec (Nankin, 2002).

NOTAS

1 De acordo com Laranjeira (1993: 147) deve-se utilizar o termo homólogo ao invés de equivalente, pois, assim, adota-se uma perspectiva funcional, não valorativa.

2 Segue-se aqui a orientação de Laranjeira (1993: 147) de se utilizar o termo homólogo ao invés de equivalente. Privilegia-se, desse modo, uma perspectiva funcional.

3 Miguel Couto Guerreiro, iá havia, em 1784, adotado a contagem até a última sílaba tônica, como nota-se nesta passagem de sua regra IX: "Contando até o acento dominante / Que basta para o verso ser constante) / Dez sílabas o heróico tem..." (Cf. Chociay, 1974: 12),

4 Bilac (1944: 64), entretanto, não o considera assim tão freqüente: "Os antigos poetas portuguezes pouco empregaram este metro; o próprio Castilho cultivou-o duas ou tres vezes. Entre nós, se não é muito commum, não deixa de ser amado". 